\title{
Erratum to: Population genetics of pike, genus Esox (Actinopterygii, Esocidae), in Northern Italy: evidence for mosaic distribution of native, exotic and introgressed populations
}

\author{
Andrea Gandolfi - Claudio Ferrari - Barbara Crestanello - Matteo Girardi • \\ Livia Lucentini $\cdot$ Andreas Meraner
}

Published online: 14 June 2017

(C) Springer International Publishing Switzerland 2017

\section{Erratum to: Hydrobiologia (2017) 794:73-92 \\ DOI 10.1007/s10750-016-3083-1}

Due to an unfortunate mistake during the production process of the original publication, Fig. 5 became distorted causing illegible legends in the subfigures $b$, $\mathrm{c} 1, \mathrm{~d} 1, \mathrm{e} 1$ and e2. The correct image and its caption is published here and should be treated as definitive by the reader.

The online version of the original article can be found under doi:10.1007/s10750-016-3083-1.

A. Gandolfi $(\square)$ · C. Ferrari · B. Crestanello · M. Girardi Department of Biodiversity and Molecular Ecology, Research and Innovation Centre, Fondazione Edmund Mach (FEM), Via E. Mach 1,

38010 San Michele all'Adige, TN, Italy

e-mail: andrea.gandolfi@fmach.it

C. Ferrari

Department of Life Sciences, University of Parma, Parco, Area delle scienze 11/a, 43124 Parma, Italy

L. Lucentini

Department of Chemistry, Biology and Biotechnologies, University of Perugia, Via Elce di Sotto, 06123 Perugia, Italy

\footnotetext{
A. Meraner

Department of Forestry, Hunting and Fisheries Office of the Autonomous Province of Bolzano, Via Brennero 6, 39100 Bolzano, Italy
} 


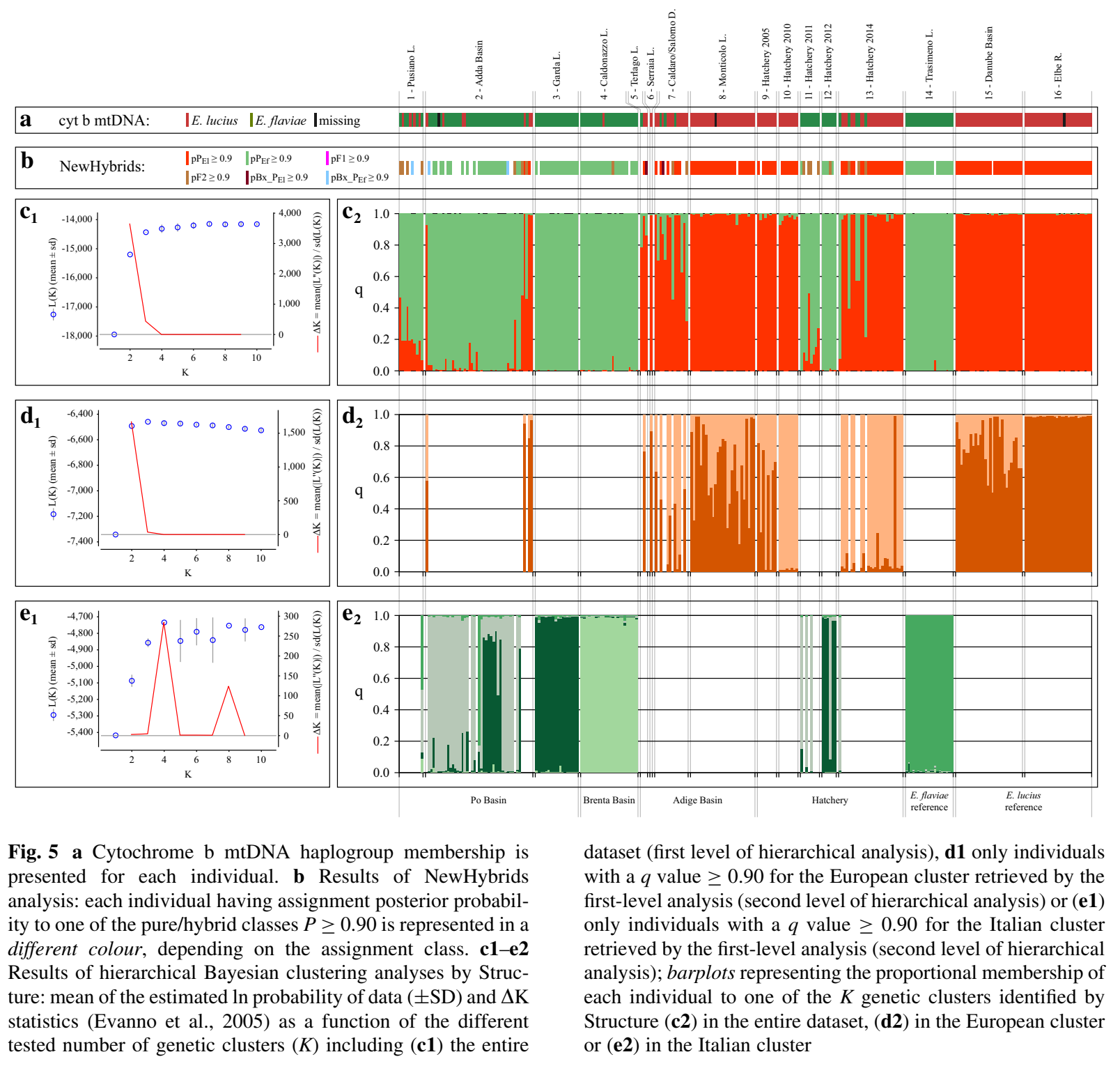

